Ann. Biol. anim. Bioch. Biophys., 1979, 19 (4 B), 1273-1278.

\title{
The induction of meiosis by ovaries of newborn hamsters and its relation to the action of the extra ovarian structures in the mesovarium (rete ovarii)
}

\author{
par A. B. FAJER, JoAnn SCHNEIDER, Diane McCALL, I. G. ANCES, S. E. POLAKIS
}

Departments of Physiology, Obstetrics-Gynecology and Biochemistry ;

University of Maryland, School of Med. Baltimore, Maryland 21201 U. S. A.

Summary. With a quantitative approach it was possible to characterize the meiosis inducing activities of the ovary and the extra ovarian structures (rete ovarii). While the ovarian inducing capacity rises with age and remains high on days 14 and 15 post partum at the end of the prophase of the first meiotic division, the rete ovarii shows meiosis inducing activity up to day 5 post partum and an inhibitory activity on meiosis onset in the ovary in the 14 and 15 day old animals.

The early activity of the rete ovarii seems to be more of a maturing nature on the germ cells in meiosis.

It has been demonstrated that meiosis will proceed in vitro (Martinovitch, 1938). However, if cultures are started before the onset of meiosis, the explant becomes sterile with the degeneration of practically all germ cells. In the hamster, if ovaries are explanted before 15 days post coifum, very few germ cells remain after 7 days of culture (Challoner, 1975).

The role of gonadotrophins and sex steroids in the meiotic process is not understood, but they do not play the role of inducers (Mauléon, 1975).

More recently it has been demonstrated that the extra ovarian structures (EOS) of the mesovarium play an important role in the onset of meiosis. Based on transplant studies of fetal ovaries in the nude mouse, it was suggested that the presence of these extra ovarian tissues called rete ovarii are necessary, not only for the onset of meiosis but also for the formation of the primordial follicles (Byskov, 1974a).

In some species - cat, mink, ferret - the rete ovarii seems to contribute heavily to the formation of the granulosa cell population (Byskov, 1974b). This seems to also be true in the mouse, but has not been studied in detail in the hamster and other species.

The rete ovarii is a term that refers to the various extra ovarian structures of mesonephric origin present in the mesovarium. It is with this meaning that the term " rete ovarii » is used and it may be taken as synonymous for extra ovarian structures in the mesovarium. In the hamster, the separation between the ovary and the structures 
in the mesovarium is very well defined and there is no confusion possible between the ovary and such extra ovarian tissues.

Hamster ovaries obtained 12 days post coifum with the rete ovarii and cultured for periods of time up to 16 days show germ cells in meiosis ( $O$ and Baker, 1976). These observations were extended to the testis. The extra ovarian tissues may induce meiosis in the fetal mouse testis (Byskov and Saxen, 1976). According to Jost et al. (1974), a meiosis inhibitory substance is present in the male and predominates due to the enclosure of the gonocytes within the cords.

Many questions related to the onset and progress of meiosis remain. The role of the ovary itself as a target organ or a participant in the process has not been evaluated. In addition, the interaction between ovary and extra ovarian structures during the early stages of ovarian development remains to be studied.

The process of initiating and arresting meiosis in the female occurs in a brief period of time. It is possible that the two mechanisms are not only time-related.

The role of the ovary in the onset of meiosis and its relation to the rete ovarii are studied in this presentation.

\section{Material and methods.}

Golden hamsters of the Engle strain were acclimatized to the laboratory and mated on proestrous. Estrous, the day of the vaginal discharge, is considered day 1 of pregnancy. Organ cultures were performed in multi-well culture plates (Falcon, 3008) using a 1.5 p. 100 . Noble Agar (Difco) for support and medium 199 with 20 p. 100 heat inactivated fetal calf serum (Gibco).

Two gonads of each age are used in each well separated from the other cocultured gonads by a stainless steel grid with 60 micra pores. Each set of cocultures is repeated in 3 wells.

Ovaries obtained on day 14 post coitum are the test ovaries. They do not show meiosis when cultured alone for periods of time as long as 14 days.

At the end of the culture period, seven days in most experiments, the tissue is placed in hypotonic potassium chloride $(0.1 \mathrm{M})$. After fixation in methanol : acetic acid $(3: 1)$, tissue is placed in 60 p. 100 acetic acid and the cell suspension pipetted on cold, wet slides. When dry, the slides are stained in Giemsa. To determine the effect of the various experimental conditions, the percentage of germ cells in meiosis is determined by counting a minimum of 1000 cells in groups of 200 .

Mean and standard error are calculated. Analysis of variance and t test using Bonferroni tables (Miller Jr, 1966) is done after arc sin conversion of the data within groups. Student $t$ test tables were used for $t$ tests between groups.

\section{Results.}

1. Meiosis inducing activity of the ovary (fig. 1). - Test ovaries were cocultured for 7 days with ovaries obtained from 5,9 and 14 day old hamsters. Their meiosis inducing activity was compared to that of fetal ovaries obtained on day 15 post coitum. 
It is clear from figure 1 that the ovaries of newborn animals show meiosis inducing capacity. There are no significant differences between the effects seen in the 3 days studied. These results are all significantly different from those obtained with fetal ovaries $\left(f_{0.01}=3.8, t(15\right.$ p. c. $)$ vs. $(5$ p. p. $)=5.80, t(15$ p. c. $)$ vs. $(9$ p. p. $)=5.97$ and $t(15$ p. c. $)$ vs. $(14$ p. p. $)=7.03)$.

Fig. 1. - Effect of ovary of various ages on the test ovary obtained at 14 days post coitum, co-cultured for seven days. Percentage \pm std. error of germ cells in meiosis in clear columns. Cells reaching diplotene stage in shaded columns. p. c., post coitum ; p. p., post partum.

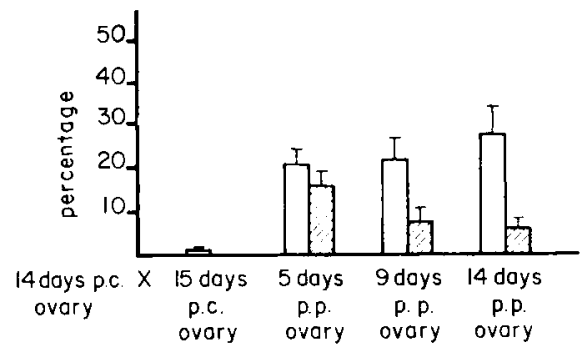

When only cells in the diplotene stage are counted, differences between new born animals are not significant at the 0.5 p. 100 level.

2. Meiosis induced by the extra ovarian structures (rete ovarii) (fig. 2). - When only the rete ovarii of 5, 9 and 14 day old hamsters is used in cocultures with the test ovaries, the 5 day old rete ovarii induces a majority of germ cells into meiosis. The finding of 80 p. 100 of germ cells in meiosis is the highest in this series. Furthermore, practically all reached the diplotene stage.

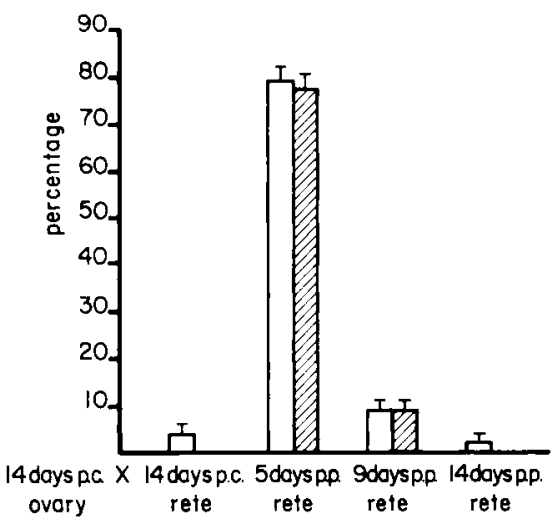

FIG. 2. - Effect of rete ovarii of various ages on test ovaries obtained at 14 days post coitum, co-cultured for seven days. Percentage \pm std. error of germ cells in meiosis in clear columns. Cells reaching diplotene stage in shaded columns. p. c., post coitum ; p.p., post partum.

In the cocultures with 9 day old rete ovarii, the 10 p. 100 of germ cells in meiosis are also at the diplotene stage. The lowest values are found in the cocultures with 14 day old rete.

When the effects of the rete ovarii are compared with those of the ovary alone, there is no significant difference between the percentage of cells in meiosis induced by the two 9 day old tissues. The differences between the effects of 5 day old rete and any of the other rete ovarii are highly significant $\left(t_{0.01}=3.82, t\right.$ (rete 5$)$ vs. (rete 14) $=32.9$, $t($ rete 5$)$ vs. $($ rete 9$)=23.8)$. By day 14 post partum, the rete has lost most of its meiosis 
inducing capacity. When these findings are compared to the action of the ovaries, the difference between the ovary and rete of 5 day old animals is equally significant $\left(t_{0.01}=4.13, t\right.$ (ov 5) vs. (rete 5) $\left.=9.6\right)$ as is the difference between 14 day old rete and 14 day old ovary ( $t$ (rete 14) vs. (ov 14) $=6.9$ ).

In these experiments, the effect of the rete ovarii obtained on day 14 post coitum is small. After seven days of culture only early leptotene slages are found in the test ovaries cultured with the rete of the same age. The results are in contrast with the observations of $O$ and Baker (1976) that saw latter stages in ovaries with their rete ovarii obtained 12 to 14 days post coitum after 12 to 16 days of culture.

3. Effects of the ovary with its rete ovarii on the test ovaries (fig. 3). - When ovaries plus rete are cocultured with test ovaries, the results show clearly the double role of the rete ovarii.

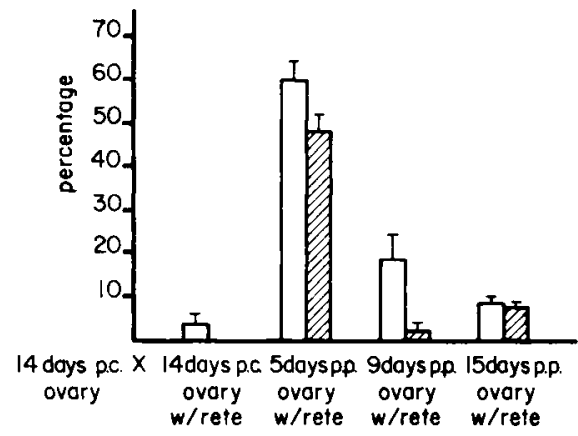

FIG. 3. - Effect of ovary plus its rete ovarii on test ovaries obtained at 14 days post partum, cocultured for seven days. Percentage \pm sid. error of germ cells in meiosis in clear columns. Cells reaching diplotene stage in shaded columns. p. c., post coitum ; p. p., post partum.

The induction of meiosis by 5 day old ovary plus rete is higher than that of the ovary alone, but slightly lower than that of rete alone. Statistically these differences were not significant. The results show an inhibition of the meiosis inducing capacity of the ovary by the 15 day old rete ovarii.

This inhibition is significant when compared to the effects of ovary alone (fig. 2), $\left(t_{0.01}=3.5,+(\right.$ ov 14$)$ vs. (rete 15) $=3.9$, df 5). The effects of the 9 day old ovaries plus rete seem to show a balance between the inducing capacity of the ovary and the developing inhibitory action of the rete ovarii.

\section{Discussion.}

Previous studies in the mouse and hamster have been confined to observing the presence of the meiosis influencing activity of the rete ovarii. Furthermore, these studies were histological in nature and consequently the results were not expressed in a quantitative manner. Using a method that separates and enlarges nuclei enabling easy identification, an initial quantitative approach could be devised.

The data give only the relative distribution of cells in meiosis. An absolute count of the germ cells would also give an indication of the rate of atresia in vitro. Even more 
information would be obtained if comparisons were made with the corresponding ovaries in vivo. This comparison can only be done on a relative basis. The ovaries in vitro show a very different distribution of oogonia and cells in meiosis. Besides the percentage of the cells in meiosis is always lower than in ovaries of comparable age in vivo.

Our time-study of the meiosis inducing action of the ovary and rete ovarii show a very distinct pattern of activities. While the activity of the ovary in vitro does not decrease significantly up to the end of meiosis, the rete ovarii shows a positive inducing activity that peaks on day 5 post partum. This extra ovarian activity is characterized by the fact that practically all germ cells - 76 p. 100 out of 80 p. 100 - have reached diplotene. This is the only instance in which the ovaries in vitro are at a more advanced stage than those corresponding ovaries in vivo. Ovaries of 5 or 6 day old hamsters have only 25 p. 100 of cells in diplotene. It appears as if the rete accelerated the completion of the first meiotic prophase. The effect of the fetal rete ovarii is minimal. Figures 2 and 3 show for the rete the total number of nuclei of oogonia that were not typical and include preleptotene and leptotene stages.

The experiments in which ovaries and their rete are used against the test ovaries confirm the inducing capacity of the 5 day old rete ovarii, in contrast to the inhibitory action of the 15 day old one. The results exclude a change in the receptivity of the oogonia to one factor, since the 9 and 14 day old ovaries alone still induce meiosis to an high degree (fig. 1).

The source of such inhibitory activity by the rete ovarii is difficult to ascertain at this time. The experiments also indicate that fetal rete ovarii does not mature well in vitro, since very little inducing activity is shown by rete ovarii or ovary plus rete obtained 14 days post coitum (fig. 2, 3).

Since the strongest inhibitory activity is seen in rete ovarii from 14 and 15 day old animals at the end of the prophase of the first meiotic division when no oogonia are present in the ovary, the function of such a substance in ovarian development remains to be clarified.

The inhibitory action of the rete ovarii may be related to the arrest of meiosis at the diplotene stage. However, the experiments presented were not designed to test this possibility. The inhibitory activity may be the same found later in the follicular fluid (Chang, 1955) and the granulosa cells (Foote and Thibault, 1969).

Thus, our results indicate that in the short period of time in which the germ cells go into meiosis and reach the diplotene stage of the prophase, three successive events take place : onset of meiosis, progression to the diplotene stage and arrest. These events seem to be provoked by different factors whose precise cellular source and chemical nature remain to be established. As stated above, it is very possible that the inhibitory action remains for life ; the fate of the other two is still to be established.

4th Workshop on « Development and maturation of the reproductive organs and functions 》 Luynes, France, octobre 1978.

Acknowledgments. - We thank Dr. A. L. Haskins for his continuous support and Dr. D. Wilson and Ms. Alden H. Reese for their help in the statistical treatment of the data. 
Résumé. Par des combinaisons in vitro de gonades ou de rete ovarii d'âges différents, il a été possible de caractériser les activités inductrices de la méiose dans l'ovaire ef les structures extra-ovariennes (rete ovarii). Tandis que la capacité d'induire la méiose croît dans l'ovaire avec l'âge et reste élevée du $14^{\mathrm{e}}$ au $15^{\mathrm{e}}$ jour après la naissance quand apparaît la fin de la prophase méiotique, le rete ovarii possède une activité méiogène jusqu'au $5^{\mathrm{e}}$ jour et une activité inhibitrice sur le démarrage de la méiose chez les animaux de 14 et 15 jours. L'activité précoce du rete ovarii paraît être plus un facteur de maturation sur les cellules germinales en méiose.

\section{References}

BYSKOV A. G., 1974a. Does the rete ovarii act as a trigger for the onset of meiosis ? Nature, 252, 396-397.

BYSKOV A. G., 1974b. The role of the rete ovarii in meiosis and follicle formation in the cat, mink and ferret. J. Reprod. Fert., 45, 201-209.

BYSKOV A. G., SAXEN L., 1976. Induction of meiosis in fetal mouse testis in vitro. Dev. Biol., 52, 193-200.

CHALLONER S., 1975. Studies of oogenesis and follicular development in the golden hamster II. Initiation and control of meiosis in vitro. J. Anat., 119, 149-156.

CHANG M. C., 1955. The maturation of rabbit oocytes in culture and their maturation, activation, fertilization and subsequent development in the fallopian tubes. J. exp. Zool., 128, 379-405.

FOOTE W. D., THIBAULT C., 1969. Recherches expérimentales sur la maturation in vitro des ovocyles de truie et de veau. Ann. Biol. anim. Bioch. Biophys., 9, 329-349.

JOST A., MAGRE S., CRESSENT M., 1974. In MANCINI R. E., MARTINI L., Male fertility and sferility. Acad. Press, p. 1.

O W., BAKER T. G., 1976. Initiation and control of meiosis in hamster gonads in vitro. J. Reprod. Fert., 48, 399-401.

MARTINOVITCH P. N., 1938. Development in vitro of the mammalian gonad. Ovary and oogenesis. Proc. roy. Soc. (B), 125, 232-249.

MAULÉON P., 1975. Importance of various oogenetic periods in the embryonic sheep gonad : control of changing mitosis in meiosis. Ann. Biol. anim. Bioch. Biophys., 15, 725-738.

MILLER Jr R. G., 1966. Simultaneous statistical inference. McGraw Hill Book Co. 